\title{
Belgeo
}

Revue belge de géographie

1 | 2015

Hazards and Disasters: Learning, Teaching,

Communication and Knowledge Exchange

\section{The Chernobyl necklace: the psychosocial experiences of female radiation emergency survivors}

Les impacts psychosociaux des accidents nucléaires sur les femmes

\section{Becky Alexis-Martin}

\section{(2) OpenEdition}

\section{Journals}

Electronic version

URL: http://journals.openedition.org/belgeo/15875

DOI: $10.4000 /$ belgeo. 15875

ISSN: 2294-9135

Publisher:

National Committee of Geography of Belgium, Société Royale Belge de Géographie

Electronic reference

Becky Alexis-Martin, «The Chernobyl necklace: the psychosocial experiences of female radiation emergency survivors », Belgeo [Online], 1 | 2015, Online since 30 June 2015, connection on 20 April 2019. URL : http://journals.openedition.org/belgeo/15875; DOI : 10.4000/belgeo.15875

This text was automatically generated on 20 April 2019.

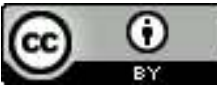

Belgeo est mis à disposition selon les termes de la licence Creative Commons Attribution 4.0 International. 


\title{
The Chernobyl necklace: the psychosocial experiences of female radiation emergency survivors
}

Les impacts psychosociaux des accidents nucléaires sur les femmes

\author{
Becky Alexis-Martin
}

\section{Introduction}

1 A modern mythology surrounds the perception of risk from exposure to ionising radiation. Fear of radiation may originate from its implementation as weaponry, during the atomic bombing of Hiroshima and Nagasaki in Japan (Slovic, 2012). However, the unusual properties, potentially mutagenic capacity and comparative newness of the radioactive materials used for energy production and defence may also contribute towards this concern. The perception of radiation as unnatural and "other" causes greater anxiety towards this hazard than most, regardless of likelihood and scale of exposure (Mobbs, Muirhead and Harrison, 2010). Attitudes towards radiation are strongly societally and culturally determined. Experience and knowledge of radiation risk is formed through both the collective opinion of a society and the individual's understanding, which may be through medical or occupational routes, media interpretation, attitudes toward resilience, and social norms. This paper characterises the way that differences in society can determine the impact that a radiation emergency will have upon women. The differences and similarities of experience are described for the two most significant nuclear accidents in history, the Chernobyl Reactor Four explosion in Ukraine and the Fukushima Daiichi accident in Japan (Sarin, 2011). Both accidents are both rated 7 on the International Nuclear and Radiological Event Scale (INES). Chernobyl and Fukushima are separated by over twenty-six years and thousands of miles, and there are also notable differences in emergency management strategy, incident severity and cultural response to these accidents. However, both accidents demonstrate parallels of 
experience for women, which may be common to female survivors of any radiation emergency.

The world's most significant accidental release of radiation occurred due to the Chernobyl Reactor Four explosion on $26^{\text {th }}$ April 1986. This accident happened as a consequence of a combination of human error and mechanical failure (Salge and Milling, 2006). An unanticipated surge of power ruptured a reactor vessel, and this ignited the combustible graphite moderator, which emitted radioactive particles and gases into the atmosphere. Radioactivity was deposited patchily across a large area of the Northern Hemisphere for two weeks after the accident (Anspaugh, Catlin and Goldman, 1988). The most significant fallout occurred across western Soviet Russia, Belarus and Ukraine; and the nearby settlements of Chornobyl and Pripyat (Clark and Smith, 1988).

The international response to Chernobyl was delayed because President Mikhail Gorbachev chose to defer the declaration of emergency for political reasons. This was despite the recently implemented Soviet policy of Glasnost, which aimed to improve transparency, decrease censorship and improve freedom of information. The emergency response was instead representative of the previous culture of within-state and beyondstate secrecy, and so information was delayed and withheld from both affected Soviet citizens and internationally (Shlyakhter and Wilson, 1992). Within Ukraine and Belorussia, the scale of the accident was played down by short news bulletins, which understated the severity of Chernobyl and claimed that it was possible to "eliminate the consequences of the accident" (Phillips, 2004). However, when large-scale evacuation of the accident's exclusion zone began, it was no longer possible to hide the scale of consequence of the accident from affected Soviet nations. The first international sign of emergency occurred when Scandinavian nuclear power stations began to report unusually high levels of background radiation. This provoked an international investigation to identify the source of the radionuclides, which eventually resulted in the Soviet's admission of the nuclear power station accident to the international community.

4 Meanwhile, forty-eight hours after the accident, the large-scale evacuation of Ukrainian and Belorussian civilians was implemented across a thirty kilometre radius surrounding the Chernobyl reactor. This radius became an exclusion zone, from which it is estimated that over 400,000 individuals were evacuated and resettled permanently (Likhtarev, Chumack and Repin, 1994). The reactor fire was initially managed by facility workers and the emergency services, but a much greater workforce was required for the emergency management effort. Members of the wider emergency services, local community, military, scientists and additional supplementary workers were conscripted to work within the exclusion zone, and were collectively known as liquidators. In total, over 300,000 individuals are estimated to have participated in liquidation work (Belyakov, Steinhäusler and Trott, 2000). Liquidators were often unaware of the health effects of excess radiation exposure and, therefore, undertook the work without adequate personal protective awareness or equipment. As a consequence, 237 liquidators suffered acute radiation syndrome (ARS), with 31 individuals dying due to exposure related pathologies within three months of the accident (Anspaugh et al., 1988; Bromet and Havenaar, 2007). It is difficult to identify the exact number of casualties and fatalities due to the physical effects Chernobyl, as there are many confounding lifestyle factors including malnourishment and high rates of alcohol and tobacco use, which all contribute to poor health (Petryna, 2011). However, some deaths should be attributed not just to exposure, but also to the opaqueness of the contemporary Soviet political machine, which had 
resulted in a culture of unwitting and unquestioning compliance amongst workers (Shlyakhter and Wilson, 1992). Across the wider population, approximately 4,000 individuals, including children and women, were diagnosed with thyroid cancer in the years following the accident (Ron et al., 1995). However, there has been a survival rate of 99\% amongst this cohort (Jacob et al., 1999: Baverstock, 1992; Little et al., 2014). One of the greatest fears following the accident was of infertility and birth defects similar to those witnessed after Hiroshima and Nagasaki, when seemingly healthy women, who were pregnant at the time of the bombing, gave birth to children with deformities as a result of radiation exposure during the first and second trimester of pregnancy (Todeschini, 1999). However, there is currently no evidence of an increase in infertility, or of birth defects amongst children born to mothers who were pregnant within the exclusion zone, during the Chernobyl accident (Cardis et al., 2006). However, the culture of secrecy within the Soviet Union at the time was ideal for the propagation of false rumour. This created unnecessary concern amongst the unexposed and allowed opportunists to exploit anxiety by peddling false 'radioprotective' cures in the wake of the accident (Phillips, 2002).

5 The most significant consequence of Chernobyl has definitely been psychosocial, with long-term social and mental health impacts upon both evacuees and the wider Soviet population. These effects are life-limiting and have resulted in increased incidence of poverty, isolation, stigma, depression, anxiety and lifestyle-related health conditions across affected regions (Bromet and Havenaar, 2007; Danzer and Danzer, 2014). The population subgroups that were most vulnerable to the psychosocial effects of the accident were evacuees, liquidators and women. Evacuees experienced the loss of control, social ties and sense of home during forced evacuations, and were subsequently labelled as helpless victims and stigmatised as unclean "Chernobylites" by residents within resettlement areas (Mould, 2000). Whilst publically feted as heroes, who were awarded state pensions and medals, many liquidators suffered post-traumatic stress disorder (PTSD) and other mental health effects, as the severity and potential health impacts of the accident gradually came to light (Kryzhanovskaya and Nakano, 1996). The social and mental health impacts upon the women of Chernobyl have been significantly greater across the spectrum of psychopathological diagnoses, which bears resemblance to the experiences of the women of Fukushima.

6 The Fukushima Daiichi nuclear accident was the most severe since Chernobyl. However, whilst Fukushima and Chernobyl are of equivalent INES, there are marked differences between the two events. The Fukushima Daiichi accident began on $11^{\text {th }}$ March 2011 due to cascading earthquake and tsunami hazards during the Great East Japan Earthquake, which was the strongest ever recorded in Japan. The Fukushima Daiichi nuclear power station was designed to withstand severe natural hazards. However, the extremity of this event resulted in damage to Fukushima Daiichi, the meltdown of three of six reactors, and the subsequent explosion of the Unit 1 reactor on $12^{\text {th }}$ March 2011 (Holt, Campbell and Nikitin, 2012). Fukushima is therefore, arguably, a more complex, if less severe, accident than Chernobyl. Japan is located on the Pacific Ring of Fire, which has converging tectonic plate boundaries and a long social and cultural legacy of seismic hazard resilience (Lay and Kanamori, 2011). Transferrable knowledge of natural hazard disaster management may have contributed to the success of Fukushima Daiichi's emergency management strategy; however, the severity of the accident was underestimated and its international significance was downplayed. This may be due, in part, to the challenge of accurately estimating atmospheric radiation following an accident but may also have a 
political component, as at the time of accident Japan was heavily reliant upon nuclear energy (Hindmarsh, 2013). However, in contrast to Chernobyl, Japanese authorities rapidly implemented an effective local emergency management plan, which included the distribution of potassium iodate tablets to block radioactive iodine uptake, restrictions upon the transport and sale of produce from the region, and the evacuation of approximately 210,000 individuals across a $20 \mathrm{~km}$ zone surrounding Fukushima Daiichi (Hamada and Ogino, 2012). Individuals living between $20 \mathrm{~km}$ and $30 \mathrm{~km}$ from the site were instructed to stay indoors and were subsequently evacuated on $25^{\text {th }}$ March 2011. After the accident occurred, a number of employees chose to remain and manage the incident. Additionally, Japanese pensioners with awareness of the potential risks of exposure and experience of the nuclear industry volunteered to form a Skilled Veterans Corps, who were referred to as the "Fukushima Fifty" (Cook and Halsall, 2012). Therefore, there was very little that unknowing about the experiences of the Fukushima emergency management workers, in contrast to the experiences of the poorly informed liquidators of Chernobyl. Fukushima Daiichi was the first time that public understanding of accidental radiation exposure was shaped by both traditional media sources and the information available on the internet. This meant that information about the accident travelled further, faster and by different pathways, due to non-traditional active citizen journalism methods including blogs, Facebook, YouTube and Twitter (Friedman, 2011). The coverage of Fukushima is therefore more extensive than that of any other previous nuclear accident, and contrasts with the glasnost violations of Chernobyl.

7 Japan's national historical experience of radiation is considerably more complex than that of Chernobyl. Whilst harnessing the power of energy generation, Japan's nuclear legacy also includes the devastating 1945 atomic bombings of Nagasaki and Hiroshima, which killed over 129,000 people. Individuals who survived the bombings were stigmatised as impure and capable of transferring their radiation exposure to others via contagion or bodily contact (Todeschini, 1999). Hiroshima and Nagasaki had a disproportionately larger population of women and children at the time, as many men were conscripted into wartime activity in the Pacific (Stimson, 1985). The Shinto cultural attitude of female uncleanliness associated with menstruation was prevalent at the time of the bombings, and radiation exposure amplified and conflated existing contamination anxieties for both genders (Todeschini, 1999). Female survivors were stigmatised and collectively called the Hibakusha, which is a derogatory term that means "the exposed", by the general population (Todeschini, 1996). Unfortunately, these beliefs were amplified when survivors who were pregnant at the time of the bombings gave birth to children with congenital defects. Consequently, women survivors were considered unfit to have children and remained unmarried; the maidens of Hiroshima (Todeschini, 1996).

Whilst there have been no physical casualties officially reported post-Fukushima, there have been significant impacts upon the position in society and mental health of female survivors, which have affected their general wellbeing and opportunities to have children and a normal family life (Ben-Ezra et al., 2015). The parallels become evident as the experiences of the women of Chernobyl and Fukushima are explored further.

\section{The Women of Chernobyl and Fukushima}

9 There is no such thing as an average radiation emergency and the experiences of female survivors are individually very diverse. However, there are a number of recurrent themes 
that arise regardless of the specific radiation emergency, which are associated with the processes of temporary or permanent evacuation, the disruption of home life, children and health. Common awareness of the potentially permanent sterilising effects of radiation and the possibility of child birth defects, are significant to the wellbeing of women, following a radiation emergency. Although improved transparency and information availability has improved the female experience of radiation emergency, there is still a great deal of stigma and misunderstanding attached to the fate of women who have been accidentally exposed to radiation.

10 The experiences of female survivors of Chernobyl can be categorised by differences that arise due to the various roles of women in society at the time of the accident. Approximately 3,000 women were conscripted for liquidation work within the exclusion zone following the accident (Welner and Page, 2013). Typically, these women were tasked with cleaning, decontamination and environmental monitoring duties, for periods ranging from a couple of weeks to several years (Kryzhanovskaya and Nakano, 1996). Women who were liquidators display both physical and psychosocial effects from their involvement of Chernobyl. Female liquidators exhibit a higher frequency of thyroid cancer and the scars from thyroid gland removal, as a result of cancer treatment, have been described by this cohort as the "Chernobyl Necklace" (Welner and Page, 2013). The social consequences for those who bear the Chernobyl necklace have not been studied, however, it is an interestingly feminised term that the women themselves use to describe their injuries. The experience of being a female liquidator may have been quite isolating, as women represented only $1 \%$ of the total number of liquidation workers (Belyakov et al., 2000). This could go some way to explain the increased incidence of PTSD amongst this group of women, the majority of whom did not have any mental health problems before the accident (Kryzhanovskaya and Nakano, 1996).

11 It is difficult to estimate the full extent of mental health effects to female survivors after Chernobyl, as conditions such as PTSD take time to manifest and there may be reluctance to share experiences of difficulty. However, women evacuees have exhibited demonstrably higher levels of long-term psychopathology than men (Viinamäki et al., 1995; Bromet and Havenaar, 2007). Some of the psychosomatic and psychological conditions that women evacuees have experienced include: depression, headaches, dizziness, fatigue, poor concentration, memory loss, irritability, mood swings, anxiety, sleep disorders, high blood pressure, dysphoria and lack of libido (Kryzhanovskaya and Nakano, 1996). Risk of poor mental health is particularly increased for women with children under the age 18, who have lived in exposed regions (Havenaar et al., 2014). It is likely that mother's concern for the health and wellbeing of their children and the consequences of exposure to radiation for the next generation are important contributory factors. However, the effects of relocation, stigma, increased stress, change in circumstance and livelihood, and increased likelihood of exposure to gendered domestic violence are also very significant to women's mental health outcomes after Chernobyl (Petryna, 2013).

12 Chernobyl also affected women's fertility. Women within the exclusion zone were not sterilised by exposure to radiation. However, the possibility of foetal exposure caused anxiety to pregnant women, who sought abortions due to concerns about potentially mutagenic defects to the foetus. There was, therefore, a large increase in abortions, delays in planned pregnancies, and a greater demand for prenatal screening following the accident (Castronovo, 1999). This fear persisted, despite evidence that children born 
within one year of the accident to mothers evacuated from the $30 \mathrm{~km}$ exclusion zone did not display more birth defects (Kreisel, 1995). Almost 30 years on from Chernobyl, exposed men are more satisfied with their lives than women, although this may be due to women's opportunities in Ukrainian society rather than the accident (Danzer and Danzer, 2014).

Whilst evacuation was compulsory and permanent after Chernobyl, over 1,200 older people defied the concerns of the Soviet authorities and returned home to their villages within the exclusion zone. The majority of the resettlers were women (Petryna, 2013). These women were ignorant of the risks of radiation exposure and proceeded to grow vegetables in the contaminated soil of their gardens and to forage within the forests for mushrooms and berries upon their return home. Many of the resettlers had lived in their villages for their entire lives before the evacuation and felt that being within the familiar confines of home was more important than evading an invisible hazard, curated by a distant and potentially untrustworthy government. Approximately 230 resettlers remain within the exclusion zone, the majority of which are elderly women who create a unique micro-society of independent and strong babusyas (Petryna, 2013). Health effects to these women are poorly documented, due to their existence on the margins of Ukrainian society. However, anecdotal evidence suggests that the babusyas of the exclusion zone are not suffering the consequences of their toxic homeland and have more fulfilling lives and better mental health than their evacuee contemporaries, so perhaps this is a victory of self-determinism over perceived risk (Petryna, 2011).

Japan is the only country that has experienced two major nuclear disasters, the atomic bombings of Nagasaki and Hiroshima in 1945, and the Fukushima Daiichi accident in 2011. Despite historical experience of the consequences of stigmatisation, it appears that women are again being more affected by the consequences of the accident (Ben-Ezra et al., 2015). Interestingly, the same themes of pregnancy, family, home and mental health reappear when the impact of Fukushima Daiichi is considered. However, the motives for these concerns are dissimilar to those of Chernobyl due to cultural and social differences.

The incidence of PTSD and depression has dramatically increased following Fukushima, due to the trauma of evacuation and resettlement (Kukihara et al., 2014). However, Japan is well-equipped to manage mental health effectively and it is likely that the one of the long-term outcomes of Fukushima may be a less significant mental health burden due to good support networks and effective public health facilities that do not stigmatise mental health (Ben-Ezra et al., 2015). However, a general stigma exists towards the evacuees of Fukushima and more can be learnt through this about the social conditions that may have led to poor mental health amongst the mothers of Chernobyl. Evacuee mothers with children have been subject to the same stigma as their Chernobylite equivalents, as resident Japanese mothers have informed evacuees that they must not allow their children to interact with the local children, for fear of contamination (Bromet, 2011). This creates a culture of exclusion and isolation, which undoubtedly impacts upon women's mental health. After Fukushima, mothers have become more protective of their children and have restricted their activities due to concerns about radiation exposure. The Japanese Ministry of Education revealed that Fukushima schoolchildren experience the highest rates of childhood obesity in Japan, which may be a consequence of a cautionary and sedentary new lifestyle, following the accident (Sakai et al., 2014). Unfortunately, the health problems associated with obesity may have a more significant impact upon this generation of children than any potential radiation exposure. 
16 Whilst the Chernobylite evacuees experienced discrimination regardless of gender, female Fukushima survivors have been subject to a resurgence of gendered negative attitudes, especially from the older generations. Hibakusha, the derogatory term for a woman exposed to radiation during the atomic bombings, has been resurrected and is now applied to describe the women of Fukushima (Ben-Ezra et al., 2015). There is evidence of gender-specific stigma against marrying women from Fukushima due to the inaccurate preconception that genetic defects can be attributed to the mother, who may consequently give birth to affected children (Ben-Ezra et al., 2015). Therefore, women from Fukushima might be perceived as damaged goods and marriage discrimination may become a future problem (Tone and Stone, 2014). In parallel with Chernobyl, there has also been an increase in gendered violence towards women following Fukushima Daiichi (Yoshihama, 2014). It can be anticipated that increased stigma, discrimination and violence towards women following Fukushima has the potential capacity to create a future legacy of mental health challenges for Japan, but only time will tell.

\section{Conclusions}

17 This paper has described and contrasted the experiences of women during the radiation emergencies of Chernobyl and Fukushima. There are a number of important parallels, which focus around the process of evacuation, the consequences of displacement and loss of home. Relocation, following the Chernobyl accident, had permanent implications for Chernobylites but, hopefully, the consequences will be shorter-term for the displaced of Fukushima. This has significant implications for the women of Fukushima as it offers hope that original family home and local social networks may someday be resumed.

Interestingly, the women survivors of Fukushima appear to experience greater external negative judgment and stigma than those of Chernobyl. This may be due to the scale of the incident as many more women were affected by Chernobyl than by Fukushima. Culture and history may also have an important part to play in determining stigma, as Japan's Shinto culture and atomic history have increased the likelihood of a repeat of negative female experience. Much of this stigma is mired in ignorance of the scale of effects of radiation upon women and is often a subconscious, rather than direct, prejudice.

The social attitudes of the two different places are also significant. Japan has a more obedient culture with very well defined social norms and there has been considerably less unregulated activity and rebellion than Ukraine. However, existing cynicism of the Soviet regime was compounded amongst the older generations and there was a significant backlash by women against the compulsory evacuation policies. This prioritisation of home over perceived safety is, currently, particular to Chernobylites within the radiation emergency scenario. However, as time progresses it may be that Fukushima survivors will also begin to relocate illicitly to their homes. Prior knowledge of Chernobyl is influencing Japan's decision to reclaim the home lands of those within the evacuation zone, by expensive decontamination of housing.

However, the women of Chernobyl fare much worse when the likelihood of depression is considered. This is due to the relatively underdeveloped mental health service provision available in Soviet Russia. In contrast to this, a comprehensive mental healthcare service is available to female Fukushima survivors. Additionally, the culture of Japan shows more 
acceptance and less stigma towards mental health, encouraging reporting and management. Both Chernobyl and Fukushima show considerably higher levels of mental health reporting and documentation for women compared to men. Perhaps there is actually a hidden and unreported mental health crisis of men following radiation emergencies? This could, potentially, go some way towards explaining the increased rates of gendered domestic violence which followed the atomic bombing, Chernobyl and Fukushima. It is also interesting to note that women affected solely by the tsunami are showing significant improvements and are developing more positive attitudes about the future, whereas nuclear evacuees have become more depressed with time. Perhaps it is too soon to truly understand the long-term psychological effects of Fukushima upon women, and only time will reveal if Fukushima has an impact upon the attitudes of fertile women, causing further birth decline in a nation of already stagnant birth rates.

However, there is a great need for further study, for while this paper begins to provide comparative insights, a complete understanding of the psychosocial experiences of women during radiation emergencies is not yet available. There is, therefore, a need to collate and contrast the diverse personal experiences of these women, from the Hibakusha of Hiroshima and Fukushima, to the female liquidators, and of course, the stealthy babusyas of the Chernobyl exclusion zone.

\section{BIBLIOGRAPHY}

ANSPAUGH L.R., CATLIN R.J. \& GOLDMAN M. (1988), "The global impact of the Chernobyl reactor accident", Science, 242, pp. 1513-1519.

BAVERSTOCK K. (1992), “Thyroid cancer in children in Belarus after Chernobyl”, World health statistics quarterly. Rapport trimestriel de statistiques sanitaires mondiales, 46, pp. 204-208.

BELYAKOV O.V., STEINHÄUSLER F. \& TROTT K.-R. (2000), “Chernobyl liquidators. The people and the doses", Proceedings of the Tenth International Congress of the International Radiation Protection Association, Hiroshima, Japan, 14-19 May 2000.

BEN-EZRA M., SHIGEMURA J., PALGI Y., HAMAMA-RAZ Y., LAVENDA O., SUZUKI M. \& GOODWIN R. (2015), "From Hiroshima to Fukushima: PTSD symptoms and radiation stigma across regions in Japan", Journal of psychiatric research, 60, pp. 185-186.

BROMET E.J. (2011), “Lessons learned from radiation disasters”, World Psychiatry, 10, pp. 83-84.

BROMET E. J. \& HAVENAAR J.M. (2007), "Psychological and perceived health effects of the Chernobyl disaster: a 20-year review", Health physics, 93, pp. 516-521.

CARDIS E., HOWE G., RON E., BEBESHKO V., BOGDANOVA T., BOUVILLE A., CARR Z., CHUMAK V., DAVIS S. \& DEMIDCHIK Y. (2006), "Cancer consequences of the Chernobyl accident: 20 years on", Journal of radiological protection, 26, 127.

CASTRONOVO F.P. (1999), “Teratogen update: radiation and Chernobyl”, Teratology, 60, pp. 100-106.

CLARK M.J. \& SMITH F.B. (1988), Wet and dry deposition of Chernobyl releases. 
COOK I. G. \& HALSALL J. (2012), “Aging in Japan”, Aging in comparative perspective, Springer, pp. 37-45.

DANZER A.M. \& DANZER N. (2014), “The Long-Run Consequences of Chernobyl: Evidence on Subjective Well-Being, Mental Health and Welfare", Mental Health and Welfare (June 25, 2014). CESIFO Working Paper Series.

FRIEDMAN S. M. (2011), “Three Mile Island, Chernobyl, and Fukushima: An analysis of traditional and new media coverage of nuclear accidents and radiation", Bulletin of the atomic scientists, 67, pp. $55-65$.

HAMADA N. \& OGINO H. (2012), "Food safety regulations: what we learned from the Fukushima nuclear accident", Journal of environmental radioactivity, 111, pp. 83-99.

HAVENAAR J.M., RUMYANTZEVA G.M., VAN DEN BRINK W., POELIJOE N.W., VAN DEN BOUT J., VAN ENGELAND H. \& KOETER M.W. (2014), Long-term mental health effects of the Chernobyl disaster: an epidemiologic survey in two former Soviet regions.

HINDMARSH R. (2013), Nuclear disaster at Fukushima Daiichi: social, political and environmental Issues, Routledge.

HOLT M., CAMPBELL R.J. \& NIKITIN. M.B. (2012), Fukushima nuclear disaster, Congressional Research Service.

JACOB P., KENIGSBERG Y., ZVONOVA I., GOULKO G., BUGLOVA E., HEIDENREICH W., GOLOVNEVA A., BRATILOVA A., DROZDOVITCH V. \&. KRUK J. (1999), "Childhood exposure due to the Chernobyl accident and thyroid cancer risk in contaminated areas of Belarus and Russia", British journal of cancer, 80, 9, pp. 1461-1469.

KREISEL W. (1995), "International program on the health effects of the Chernobyl accident", Stem cells (Dayton, Ohio), 13, pp. 33-39.

KRYZHANOVSKAYA L. \& NAKANO Y. (1996), "Mental health of liquidators of the Chernobyl disaster", Acta medica nagasakiensia, 41, pp. 15-19.

KUKIHARA H., YAMAWAKI N., UCHIYAMA K., ARAI S. \& HORIKAWA E. (2014), “Trauma, depression, and resilience of earthquake/tsunami/nuclear disaster survivors of Hirono, Fukushima, Japan", Psychiatry and clinical neurosciences, 68, pp. 524-533.

LAY T. \& KANAMORI H. (2011), "Japan earthquake”, Physics today, 64, 33.

LIKHTAREV I.A., CHUMACK V.V. \& REPIN V.S. (1994), "Analysis of the effectiveness of emergency countermeasures in the $30-\mathrm{km}$ zone during the early phase of the Chernobyl accident", Health physics, 67, pp. 541-544.

LITTLE M.P., KUKUSH A.G., MASIUK S.V., SHKLYAR S., CARROLL R.J., LUBIN J.H., KWON D., BRENNER A.V., TRONKO M.D. \& MABUCHI K. (2014), "Impact of Uncertainties in Exposure Assessment on Estimates of Thyroid Cancer Risk among Ukrainian Children and Adolescents Exposed from the Chernobyl Accident", PLoS ONE, 9, e85723.

MOBBS S., MUIRHEAD C. \& HARRISON J. (2010), Risks from ionising radiation, Health Protection Agency.

MOULD R.F. (2000), Chernobyl record: the definitive history of the Chernobyl catastrophe, CRC Press.

PETRYNA A. (2011), “Chernobyl's survivors: Paralyzed by fatalism or overlooked by science”, Bulletin of the atomic scientists, 67, pp. 30-37.

PETRYNA A. (2013), Life exposed: Biological citizens after Chernobyl, Princeton University Press. 
PHILLIPS S.D. (2002), "Half-Lives and Healthy Bodies: Discourses on Contaminated Food and Healing in Postchernobyl Ukraine”, Food and foodways, 10, pp. 27-53.

PHILLIPS S.D. (2004), “Chernobyl's Sixth Sense: The Symbolism of an Ever-Present Awareness”, Anthropology and humanism, 29, pp. 159-185.

RON E., LUBIN J.H., SHORE R.E., MABUCHI K., MODAN B., POTTERN L.M., SCHNEIDER A.B., TUCKER M.A. \& BOICE J.D. Jr (1995), “Thyroid cancer after exposure to external radiation: a pooled analysis of seven studies", Radiation Research, 141, pp. 259-277.

SAKAI A., OHIRA T., HOSOYA M., OHTSURU A., SATOH H., KAWASAKI Y., SUZUKI H., TAKAHASHI A., KOBASHI G. \& OZASA K. (2014), "Life as an evacuee after the Fukushima Daiichi nuclear power plant accident is a cause of polycythemia: the Fukushima Health Management Survey", BMC Public health, 14, 1318.

SALGE M. \& MILLING P.M. (2006), "Who is to blame, the operator or the designer? Two stages of human failure in the Chernobyl accident”, System Dynamics Review, 22, pp. 89-112.

SARIN R. (2011), "Chernobyl, Fukushima, and beyond: A health safety perspective”, Journal of cancer research and therapeutics, 7, 109.

SHLYAKHTER A. \& WILSON R. (1992), "Chernobyl and glasnost: the effects of secrecy on health and safety", Environment: science and policy for sustainable development, 34, pp. 25-30.

SLOVIC P. (2012), "The perception gap: Radiation and risk", Bulletin of the atomic scientists, 68, pp. 67-75.

STIMSON H.L. (1985), "The decision to use the atomic bomb", SAIS Review, 5, pp. 1-15.

TODESCHINI M. (1996), "Death and the Maiden: Female Hibakusha as Cultural Heroines and the Politics of A-Bomb Memory", Hibakusha cinema: Hiroshima, Nagasaki and the nuclear image in Japanese film, pp. 222-252.

TODESCHINI M.M. (1999), Bittersweet crossroads: women of Hiroshima and Nagasaki, Harvard University.

TONE M. \& STONE T. (2014), "What we can learn about recovery: Lessons from the Fukushima survivors”, Nursing \& health sciences, 16, pp. 52-55.

VIINAMÄKI H., KUMPUSALO E., MYLLYKANGAS M., SALOMAA S., KUMPUSALO L., KOLMAKOV S., ILCHENKO I., ZHUKOWSKY G. \& NISSINEN A. (1995), "The Chernobyl accident and mental wellbeing - a population study”, Acta Psychiatrica scandinavica, 91, pp. 396-401.

WELNER M. \& PAGE J. (2013), “Disaster Psychiatry”, Disaster preparedness for health care facilities, 469.

YOSHIHAMA M. (2014), "Gender-based violence following the Great East Japan Disasters of March 2011", $142^{\text {nd }}$ APHA Annual Meeting and Exposition (November 15-November 19, 2014), APHA.

\section{ABSTRACTS}

Whilst the significance of physical exposure to ionising radiation can be empirically ascertained, radiation emergencies also have significant psychosocial impacts which are politically, socially and culturally determined. The nuclear reactor accidents of Chernobyl in 1986 and Fukushima in 2011 have had differential consequences for women, due to differences in space, place and time. This paper characterises, contextualises and compares the psychosocial effects of Chernobyl and Fukushima for female survivors, demonstrating the significant impacts of radiation emergencies. 
Une compréhension plus profonde des effets des accidents nucléaires sur les femmes peut limiter leurs impacts négatifs sur elles dans l'avenir, en particulier pour ce sous-groupe démographique. Les accidents de réacteurs nucléaires de Tchernobyl en Ukraine (1986) et de Fukushima au Japon (2011) ont eu des impacts différentiels sur les femmes à proximité immédiate et au-delà de l'accident. Cet exposé décrit, contextualise et compare les conséquences de ces deux accidents de réacteurs nucléaires sur les femmes.

INDEX

Keywords: women, Fukushima, Chernobyl, spatiotemporal, emergency, radiation protection, risk

Mots-clés: femmes, Fukushima, Tchernobyl, spatio-temporel, urgence, protection contre les radiations, risques

\section{AUTHOR}

\section{BECKY ALEXIS-MARTIN}

University of Southampton, UK, Becky.Martin@soton.ac.uk 